\title{
Improvement of Biodiesel Product Yield during Simple Consecutive-Competitive Reactions
}

\author{
Kal Renganathan Sharma \\ Electrical Program, San Jacinto College, Pasadena, TX, USA \\ Email: jyoti_kalpika@yahoo.com
}

Received 18 December 2013; accepted 14 December 2015; published 17 December 2015

Copyright (C) 2015 by author and Scientific Research Publishing Inc.

This work is licensed under the Creative Commons Attribution International License (CC BY). http://creativecommons.org/licenses/by/4.0/

(c) (i) Open Access

\begin{abstract}
Biodiesel is a renewable fuel that can be made from vegetable oil and waste restaurant greases by catalysed transesterification reactions. Over 5 billion gallons of biodiesel was produced in 2010 . The European Union and United States are seeing the sigmoidal portion of the growth curve in biodiesel production. Economic analysis such as profitability and annualized worth (AW) of a biodiesel plant in Taiwan is presented. With the revenue from glycerine byproduct recovery and with lower raw material costs, biodiesel may be profitable especially during days of higher gasoline prices. Multiple reactions of the consecutive-competive type may be used to model the methonolysis of trigylcerides. The reaction rate constant ratios and residence time in the reactor are important parameters in determining higher selectivity of FAME, fatty acid methyl ester product yield over glycerol by-product production. Illustrations of higher FAME yield, higher glycerol yield and cross-over from FAME to glycerol are shown for some values of reaction rate constant ratios and reaction scheme from triglycerides to diglycerides, monoglycerides and glycerol along with formation of FAME in each step by addition of methanol and catalyst is shown. Product distribution curves are presented in Figures 2-5 for different values or reaction rate constant ratios.
\end{abstract}

\section{Keywords}

Biodiesel, Transesterification Reactions, Consecutive-Competitive Reactions, Jatropha Curcas Oil, Genomics, Centrifugal Separation, Optimization, Profitability, Method of Laplace Transforms

\section{Introduction}

A century ago, R. Diesel successfully used vegetable oil as fuel for his engine. Prior to WWII, vegetable oils 
were blended with diesel fuels time and again. Biodiesel is an interesting choice for use as alternate energy. Biodiesel is a mixture of FAME, fatty acid methyl esters. It is an EPA; Environmental Protection Agency designates advanced biofuel. It can be derived from vegetable oil or animal fats. It can be used from a spectrum of resources that include waste fats, greases and agricultural oils. Biodiesel can save money for the consumer. For example, Ray Mabus, secretary of the Navy testified in Capitol Hill that by purchasing $20 \%$ biodiesel blend, savings of 13 cents a gallon and $\sim \$ 30,000$ total in winter in heating oil costs were realized.

Oil reserves are expected to be depleted by the year 2050 at the current levels of production. The crude oil reserves are estimated at 4.16 trillion liters worldwide [1]. Global consumption is 84.6 million barrels/day. Earth's entire oil reserves according to one's estimate are 1.2 trillion barrels without oil sands and 3.74 trillion barrels with oil sands. At the present rate of consumption, the oil reserves will be depleted in the next 38.8 - 122.2 years. Search is on for alternative oil finds. Per geological survey 3 - 4.5 billion barrels is found in Montana and North Dakota. If oil shale can be used as source of oil, the reserves can last for 110 more years. Oil finds have been found in Russia, Columbia and Africa. According to the big rollover theory, global oil production is already past its peak production [2]. M. K. Hubbert, Shell Oil Co., Houston, TX, studied the exhaustion of oil fields. Initial oil find, exploitation and exhaustion phases were identified. This followed the bell curve. He concluded that United States would peak in its oil production in 1970. The curve is called the Hubbert cruve. The peak is also called the rollover. Lot of world oil experts feel that we are past the peak production. Each year we have found less oil and have pumped less oil.

Largest known reserves of crude oil are located in the Middle East, along the equator and Russia and its neighbors. Transportation of crude oil has not been without spills. In 1989, the Exxon Valdez dumped 11 million gallons of oil into the waters and onto the shores of Alaska. 85 million gallons of oil onto previously pristine Arctic tundra was spewed because of a rupture in 1994 in a pipeline in Russia. In 1994, Exxon was ordered to pay $\$ 5$ billion for Alaskan oil spill. 206 million gallons of oil was spilled in the recent deepwater horizon oil spill in the Gulf of Mexico by BP Americas in 2010. This was the worst environmental disaster ever in the history of technology. This was attributed to a rig explosion. The gusher was from the ocean floor. Wars had been fought to prevent monopoly of oil supply. Analagous to how in the history of mankind stone age gave way to iron age, oil age might be eclipsed by sustainable energy. Man dropped the use of stones when he learnt the use of iron. Air pollution has been found as a result of continued and increased use of petroleum. Global warming has been concluded as a problem because of significant increase in concentration of $\mathrm{CO}_{2}$ in the earth's atmosphere [3]. The principles of Sustainable Engineering were developed at the Sandestin Conference of 2003 [4]. This ought to set the direction of engineers who work on developing sustainable alternatives to current engineering practices. Energy is considered a primary component of sustainable engineering. This is because of:

1) the pollution problems that arise from current methods of consumption of energy such as acid rain formation from emission of oxides of sulfur and nitrogen and;

2) the depleting reserves of fossil fuel such as bituminous coal, petroleum, peat, lignite, anthracite, oil shale, natural gas, etc. In most formulations of sustainability the use of renewable energy resources is desirable. The Sandestin principle states that, "Minimize depletion of natural resources".

Renewable energy resources may be viewed as fuels that are produced at rates equal to or greater than the rates at which they are consumed. Thus there is no "net depletion" of the resources with the passage of time. For example, biomass production rates may jeopardize food supplies and hence have biomass fall out of the column of renewable resources and into the column of non-renewable energy resource. Sandestin principle of life cycle analysis may be applicable for evaluation of biomass as energy resource.

\section{Biodiesel}

Renewable Fuel standard makes good policy as it preserves the ecosystem from the advantages of life cycle use. Biodiesel is nontoxic. It has low emission profiles and is environmentally benign [5]. It is recommeded for use as a substitute for petroleum-based diesel because it renewable and biodegradable. One of the methods of preparation of biodiesel is the transesterification of triacylglycerides in vegetable oil or animal fat with an alcohol such as methanol in the presence of an alkali or acid catalyst. The products are FAME (s) and are called biodiesel. Glycerin is formed as byproduct. Alkali catalysts used are $\mathrm{NaOH}$ or $\mathrm{KOH}$.

$$
\begin{array}{r}
\text { Triglyceride }+\underset{(\text { methanol) }}{\mathrm{CH}_{3} \mathrm{OH} \rightarrow} \text { 3R-COOCH}{ }_{3}+\mathrm{C}_{3} \mathrm{H}_{5}(\mathrm{OH})_{3} \\
\text { Flycerin }
\end{array}
$$

Three synthesis methods are reported for commercial manufacture of biodiesel. These are in followings. 


\subsection{Method 1: Transesterification of Vegetable Oil}

Raw oil was mixed with methanol in the presence of catalyst such as sodium methylate in order to produce the FAME. Glycerin is formed as a by-product. A two or three stage process of reaction and centrifugal separation is used. Centrifugal separation is used to separate the glycerin and biodiesel layers by gravity differences. More degree of separation can be achieved by increased torque of the rotor [6]. A trade-off is seen between utility cost for rotor speed and purity level. Optimal operation of rotor can be derived at for maximum revenue. At end of the second stage [7] with 99.2\% - 99.6\% conversion the mixture is passed through a vacuum distillation tower in order to separate the unreacted methanol, recover the sodium methylate catalyst and recycle the unreacted oil. B \& P Process patented a process [8] to make biodiesel with less equipment, more yield and at a higher purity. They use a higher temperature than the boiling point of methanol and increased pressure of the reactor in order to keep the methanol from boiling. The centrifugal separator was made with perforated concentric cylinders. The separation process was effected in a counter-current manner. This makes the throughput higher and use less floor space. The glycerin passes through the rims and the biodiesel separates out through the axial region of the separator. The reaction is between the triglycerides present in the oil and methanol. Spectrum of different feedstock types have been used for the vegetable oil. This ranges from waste cooking oil to jatorpa crop cultivated with a targeted purpose of generating fuel. Feedstock types used are: 1) Soybean oil; 2) Rapseed Oil; 3) Sun flower oil; 4) Coconut Oil; 5) Palm Oil; 6) Tung Oil. The catalyst used can be alkali, acid or enzyme. When the FFA, free fatty acid content is greater than $1 \%$ the acid catalyst would be better [9]. Alkaline catalyst is used in commercial plants. Alkaline catalysts are preferred when the FFA, free fatty acid content in the feedstock is less than $0.5 \mathrm{wt} \%$. Process is sensitive to water and FFA. Saponification of ester may occur in presence of water.

\subsection{Method 2: Pyrolysis/Thermal Cracking of Vegetable Oil}

Since WWI, World War I, many investigators have studied the pyrolysis of vegetable oils in order to obtain biodiesel. Thermal cracking of tung oil calcium soaps were reported in 1947. Tung oil was sapponified with lime and then thermally cracked in order to yield a crude oil. Pyrolysis methods have been found to result in more biogasoline compared with biodiesel [10]. Pyrolysis usually involves heating in the absence of oxygen. Soybean oil was thermally decomposed and separated by distillation. About $75 \%$ of the distillate was hydrocarbons such as alkanes and alkenes. Vegetable oils can be catalytically cracked into useful fuels. Catalyst used is silica/ alumina and plam and copra oils were used. Condensed organic phase can be fractionated into biogasoline and biodiesel.

\subsection{Method 3: Physical Blending and Emulsification Process}

The alternate to use fuel for food has been discussed [10]. During the oil emargo Caterpillar Brazil in South Africa used pre-combustion chamber engines with a blend of $10 \%$ vegetable oil in order to maintain total power without any alterations to the engine. $20 \%$ vegetable oil and $80 \%$ diesel fuel blends were successfully tested. $50 / 50$ blends were also tested. Diesel fleet was powered with filtered frying oil at 95/5 blend with diesel. Polymerization of polyunsaturated vegetable oil lead to viscosity increase and was problematic. Vegetable oil has $80 \%$ of calorific value of diesel fuel. After prolonged operation of direct-injection engines problems such as coking, trumpet formation on injectors, carbon deposits, oil ring sticking and thickening and gelling were found. 1:2 and 1:1 blends of degummed soybean oil and diesel fuel were tested for engine performance in a 6 cylinder, 6.6 liter displacement, direct-injection, turbocharged prime mover made from John Deere for 60 hours. Incomplete combustion, unwanted polymerization and gum formation were noted when using vegetable oil directly as fuel. Microemulsions of vegetable oil with solvents such as methanol were studied. Microemulsion was defined [10] as a dispersion of optically isotropic fluid microstructures in 1 - $150 \mathrm{~nm}$ size range in colloidal equilibrium when two normally immiscible liquids and amphiphiles are mixed. Micellar formation leads to improvements in spraying.

\section{Forecast for Commercial Production of Biodiesel}

Over the past decade the world production of biodiesel has gone up from 15,200 barrels per day in the year 2000 to 300,000 barrels per day in 2010. In terms of volume this is about 5 billlion gallons in 2010. In the past two years, biodiesel production has exceeded targets. Production plants are present in nearly every state. $1000 \mathrm{~s}$ of 
jobs are created. The sigmoidal growth of the biodiesel volume is seen from 2006. Biodiesel is designated by ASTM D 6751. New laws and mandates on biodiesel came about in Brazil, China, United States, Argentina. Germany and Brazil are the world's leading biodiesel producers. Federal Excise tax credits are provided for producers and distributors of agri-biodiesel at $\$ 1$ for every gallon of biodiesel they blend with regular diesel. Forecasts of global dynamics of biodiesel production are available for 2015-2020 by feedstock used such as vegetable oil feedstocks, jatorpa oil, algae biodiesel and cellulose. The expected growth rate of biodiesel production in the world is about 6\% between 2009-2018 according to OECD, Organization for Economic Cooperation and Development. By 2017 biodiesel production is expected at 25 billion liters. European biodiesel board estimated that the production of biodiesel in EU is about 9.6 milllion tons in 2010. By the year 2022, biofuel production is projected to consume a significant amount of total world production of sugar cane (28\%), vegetable oils (15\%) and coarse grains (12\%) [11].

In India the former President of India, ABJ Abdul Kalam during his address to the nation on National Science Day, Feb' 28th 2006 [12] called for an increase in output of biodiesel from jatorphha crop from current levels of 2 tons per hectare to 4 - 6 tons per hectare. The oil content of most jatorpha varities ranges from $25 \%-35 \%$. Research in selection, intra-specific, inter-specific hybridization and mutation breeding is needed to develop varieties with more than $45 \%$ oil content so that a recovery of $35 \%$ under mechanical expelling. India has 60 million hectares of wasteland of which 30 million hectares are available for energy crops such as jatorpha. Cars that can run on biodiesel need be developed and encouraged. The Indian Railways runs passenger trains with diesel engine with 5\% blend of biodiesel. 15 million jatorpha saplings are planted in railways' land.

President B. Obama as a senator endorsed the budding biodiesel industry at a new biodiesel plant in Cairo, IL in 2006 [13]. The renewable energy group announced that is would build a 60 million gallon per year refinery and had raised \$100 million in financing. Bunge Ltd., a major food processor and other venture capital firms were the contributors. About 76 biodiesel plants were in production in 2006, up from 22 in 2004. A biodiesel plant on an average costs up to $\$ 20$ million to build and yields 30 million gallons per year of fuel. Biodiesel serves an important need of meeting the energy security of United States and the developing countries in the world.

\section{Process Analysis}

The electrical utility costs increases in a non-linear manner with increase in rotor speed in centrifuge used to separate glycerol from FAME. More separation is achieved more utility costs but more revenue. A point of optimal operation can be arrived at for maximum revenue. This may vary depending on the price of gasoline at the pump at a given time. The reactions in the reactor during biodiesel production may be modeled as scheme of multiple reactions of the consecutive-competitive/series-parallel type [14]. The methanol can be assumed to be in excess. Hence the reactions shown below can be assumed to obey the pseudo first order kinetics. The concentration of methanol can be lumped with the intrinsic second order reaction rate constant to give a pseudo first order lumped rate constant. The catalytic effect is also captured here. The reactions are modeled as follows (Equation (1)):

$$
\begin{aligned}
& \mathrm{A}+\mathrm{B} \stackrel{k_{1}}{\longrightarrow} \mathrm{P}+\mathrm{R} \\
& \mathrm{R}+\mathrm{B} \stackrel{k_{2}}{\longrightarrow} \mathrm{P}+\mathrm{S} \\
& \mathrm{S}+\mathrm{B} \stackrel{k_{3}}{\longrightarrow} \mathrm{P}+\mathrm{T}
\end{aligned}
$$

where A-triglyceride, B-methanol $\left(\mathrm{CH}_{3} \mathrm{OH}\right), \mathrm{R}-1,2$ and 1,3 diglyceride, S-monoglyceride, P-(FAME), T-glycerol.

It may be assumed that once the product $\mathrm{P}$ is formed it does not participate in the reaction any further. The FAME is harvested from the kettle. As glycerol (T) can be sold for profit this scheme is of more interest. This reaction set is applicable for successive attacks of a compound by a reactive material. In this case the reactive material is methanol and the compound is triglyceride. The kinetics of the reactions can be written as follows:

$$
\begin{aligned}
& \frac{\mathrm{d} C_{A}}{\mathrm{~d} t}=-k_{1} C_{A}, \frac{\mathrm{d} C_{R}}{\mathrm{~d} t}=k_{1} C_{A}-k_{2} C_{R} \\
& \frac{\mathrm{d} C_{S}}{\mathrm{~d} t}=k_{2} C_{R}-k_{3} C_{S}, \quad \frac{\mathrm{d} C_{T}}{\mathrm{~d} t}=k_{3} C_{S} \\
& C_{P}=C_{A 0}-C_{R}-C_{S}-C_{T}-C_{A}
\end{aligned}
$$


It is assumed that the initial concentration of triglycerides is $C_{A 0}$ and that of diglycerides, monoglycerides, glycerol is zero at time zero. The four ordinary differential equations in Equation (2) can be written in the state space form as follows:

$$
\frac{\mathrm{d}}{\mathrm{d} t}\left(\begin{array}{l}
C_{A} \\
C_{R} \\
C_{S} \\
C_{T}
\end{array}\right)=\left(\begin{array}{cccc}
-k_{1} & 0 & 0 & 0 \\
+k_{1} & -k_{2} & 0 & 0 \\
0 & +k_{2} & -k_{3} & 0 \\
0 & 0 & +k_{3} & 0
\end{array}\right)\left(\begin{array}{l}
C_{A} \\
C_{R} \\
C_{S} \\
C_{T}
\end{array}\right)
$$

The eigenvalues of the rate matrix in Equation (3) can be seen to be $-k_{1},-k_{2},-k_{3}$ and 0 . Since three eigenvalues are negative and one is zero the system can be seen to be of the integrating type [15]. This is an example of three-step reaction where the final T, glycerol and P (FAME) are desired. The addition policy of methanol along the length in case of PFR, plugflow reactor and the timings in the case of CSTR can influence the product mix. The method of mixing the reactants such as slow mixing of A to B, slow mixing of B to A and rapid mixing of $\mathrm{A}$ and $\mathrm{B}$ may be important design criteria. In order to obtain more yield of $\mathrm{P}$ the points where $\mathrm{R}$ and $\mathrm{S}$ will reach a maxima need be avoided as operating points.

\section{Economic Analysis}

The cost of raw materials is a critical factor in the profitability of biodiesel manufacture. Twelve reports were reviewed [16] [17] on economic feasibility of biodiesel production using different feed stocks and scales of operation. The production costs for conversion to biodiesel from different feedstocks are given in Table 1 . At the time of the study in 1999 the projected costs for biodiesel from oilseed or animal fats have a range from 30 - 69 cents per liter. The estimates include the soymeal and glycerin credits expected. Crushing and esterification facility is by retrofit of existing tallow facility. Cost of biodiesel from vegetable oil and waste grease are 54 - 62 cents per liter. When the pre-tax price of diesel is 18 cents per liter the biodiesel venture is not profitable.

Significant factors that contribute to the bottom line of the biodiesel production were identified in [18]. These include the cost of raw materials, plant size, credit received for glycerine as by-product sales. When waste cooking oil was used the material costs went down. Restaurant greases cost less than food-grade canola and soybean oils. The first factory that produced biodiesel at 300 tons per year from waste cooking oil was started in Chiayi county of Taiwan in October of 2004. About 700 garbage trucks were fueled from biodiesel in 2005 in Taiwan.

\section{Annual Worth, AW of a Bio-Diesel Plant in Taiwan [19] \\ Basis}

Biodiesel is produced by transesterification reactions. Triglycerides presented in virgin soybean oil are reacted with anhydrous alcohol such as methanol, ethanol, proponal etc to form FAME, fattyacid methyl esters, or biodiesel and glycerol. The alkali catalyst used was sodium hydroxide, $\mathrm{NaOH}$. It can potentially be used as an alternate fuel to the ones currently in vogue that tend to be culprits of pollution causing global warming, acid rain, greenhouse gas emissions etc. Biodiesel is an attractive fuel due to its environmental benefits it has to offer. It is prepared from renewable energy resources such as vegetable oil. Using the information provided in Table 2 annualized worth AW of the biodiesel plant is calculated. The plant is expected to last for 20 years. The interest rate for equivalence calculations can be taken as 3.0\%. The main cost [20] in these plants is the raw material costs. The AW analysis is completed using a MS Excel spreadsheet as shown in Table 2. The capital cost is obtained

Table 1. Review of 12 different routes to biodiesel.

\begin{tabular}{cccc}
\hline & Feedstock (Type) & Per Liter Production Cost \\
2 & Soybean Oil & 30 cents -37 cents \\
3 & Animal Fats & $40-63$ cents \\
4 & Canola Oil, Sunflower Oil & 69 cents \\
\hline
\end{tabular}


Table 2. Cost and revenue data for biodiesel production in Taiwan.

\begin{tabular}{ccc}
\hline A & Description & Cost \\
\hline A1 & Material Costs ( 6.8 milion) & \\
A2 & Soybean Feedstock & $\$ 6,234,000$ \\
B & Methanol, Catalyst and Solvent & $\$ 564,000$ \\
& Capital Equipment (per year) & $\$ 765,000$ \\
C & Reactors, Distillation Column, & \\
D & Heat Exchangers, Separators, Pumps & $\$ 564,000$ \\
E & Labor Costs & $\$ 124,000$ \\
& Utilties & $\$ 431,000$ \\
\hline
\end{tabular}

by using the SUM command from cells D4 to D10. These are the costs of reactors, washing column, distillation column, heat exchangers, pumps, vacuum systems. The capital cost of $\$ 765,000$ is amortized over 20 year period by using the capital recovery factor. The capital recovery factor is obtained from Table A-7 in Appendix A in [11] for $(\mathrm{A} / \mathrm{P}, 3 \%, 20)$.

This was found to be 0.067216 . The materials costs include the soybean oil, methanol, catalyst and solvent. The Annual costs are obtained by adding the materials cost, labor costs, utility costs and overhead costs. The annual revenue is obtained by adding the sales of biodiesel and glycerin. The AW was calculated. The AW is about \$1.915 million. Thus it is profitable to operate the biodiesel plant as described in Taiwan.

\section{Economic Evaluation of Biodiesel Production from Waste Cooking Oil}

The study of alternate fuel sources to gasoline and coal is of national importance given the supply and demand characteristics of fuels that are used extensively. Biodiesel is derived from vegetable oil or animal fats. It is recommended for use as a substitute for petroleum-based diesel because it is renewable and biodegradable. The common method of preparation of biodiesel is the transesterification of triacylglycerols in vegetable oil or animal fat with an alcohol such as methanol in the presence of an alkali or acid catalyst. The products are FAME, s and are called biodiesel. Glycerin is formed as a byproduct. Sodium hydroxide or potassium hydroxide is used as alkali catalyst. A recent study [17] evaluated the economic feasibility of a plant producing approximately 22 million pounds per year of biodiesel. Tallow was transesterified with methanol in the presence of an alkali catalyst. A second plant is based on canola seed used as the raw material. A by-product credit can be awarded for glycerin produced from seed crushing. A summary of the capital investment, process cost, revenue accrued of the three different plants are shown in Table 3. The capital cost can be assumed to pay off over a 30 year period at an interest charge of $6 \%$ per year.

Which process is the most profitable?

It is assumed that the capital cost is amortized at an interest rate of $6 \%$ per year for 30 years.

Plant I (A/P, 6\%, 30) from Table A-10 in [11] the capital recovery factor can be seen to be 0.072649

$$
\begin{gathered}
\text { Profit }=2 \times 22-12 \times(\mathrm{A} / \mathrm{P}, 6 \%, 30)-34+6=15.128 \text { million } \\
\text { Revenue }- \text { capital recovery }- \text { cost of production }+ \text { by-product credit }=\text { profit }
\end{gathered}
$$

Plant II (A/P, 6\%, 30) from Table A-10 in [11] the capital recovery factor can be seen to be 0.072649

$$
\text { Profit }=4 \times 1.7-1 \times(\mathrm{A} / \mathrm{P}, 6 \%, 30)-5.95+0.9=1.68 \text { million }
$$

Revenue - capital recovery - cost of production + by-product credit $=$ profit

Plant III (A/P, 6\%, 30) from Table A-10 in [11] the capital recovery factor can be seen to be 0.072649 
Table 3. Economic Evaluations for biodiesel production plants.

\begin{tabular}{cccc}
\hline & $\begin{array}{c}\text { Plant I } \\
\text { Alkali Catalyzed } \\
\text { Continuous Process }\end{array}$ & $\begin{array}{c}\text { Plant II } \\
\text { Alkali-Catalyzed } \\
\text { Batch Process }\end{array}$ & $\begin{array}{c}\text { Plant III } \\
\text { Alkali-Catalyzed Continuous } \\
\text { Process }\end{array}$ \\
Plant Capacity & 22 million pounds per year & 1.7 million pounds per year & 2.2 million pounds per year \\
Raw Material Used & Beef Tallow & Canola Oilseed & Animal Fats \\
Total Capital Cost & $\$ 12$ million & $\$ 1$ million & \$3illion \\
Total Manufacturing Cost & $\$ 34$ million & $\$ 5.95$ million & $\$ 12$ million \\
Glycerin Credit & $\$ 6$ million & $\$ 4 / l$ million & $\$ 3 / \mathrm{lb}$ \\
\hline
\end{tabular}

Profit $=3 \times 2.2-3.12 \times(\mathrm{A} / \mathrm{P}, 6 \%, 30)-3.4+1.2=4.17$ million

Revenue - capital recovery - cost of production + by-product credit $=$ profit

So Plant I is the most profitable followed by Plant III and then Plant II.

\section{Selectivity of Biodiesel over Glycerin}

It can be seen from the economic analysis the yield of biodiesel compared with other by-products such as glycernin can be a critical design criteria in making these plants more profitable. The reaction sequence for formation of FAME, fatty acid methyl ester from triglycerides found in palm oil and other feedstock involve the formation of diglycerides, monoglycerides and glycerin in sequence with FAME produced in each intermediate step (Darnoko and Chanya [21]). The reaction scheme can be represented as shown in Figure 1. The reactions are catalyzed. The catalyst type depends on the FFA content in the feedstock. The triglycerides species is represented with symbol $A$, diglycerides with $\mathrm{R}$, monoglycerides with $\mathrm{S}$ and glycerin with $\mathrm{T}$. The product FAME formed in each step is given by $\mathrm{P}$ and the methanol used is given as $\mathrm{B}$.

The scheme of reactions can be modeled as shown in Equation (1) as a consecutive-competitive type [14]. The reaction rate expressions in Equation (2) can be written in dimensionless form as follows after making the following substitutions:

$$
\begin{aligned}
& X_{A}=\left(\frac{C_{A 0}-C_{A}}{C_{A 0}}\right) \\
& X_{R}=\left(\frac{C_{R}}{C_{A 0}}\right) \\
& X_{S}=\left(\frac{C_{S}}{C_{A 0}}\right) \\
& X_{T}=\left(\frac{C_{T}}{C_{A 0}}\right) \\
& X_{P}=\left(\frac{C_{P}}{C_{A 0}}\right) \\
& \tau=k_{1} t \\
& \kappa=\left(\frac{k_{2}}{k_{1}}\right) \\
& \omega=\left(\frac{k_{3}}{k_{1}}\right)
\end{aligned}
$$

In dimensionless form the rate expressions given in Equation (7) can be seen to become: 


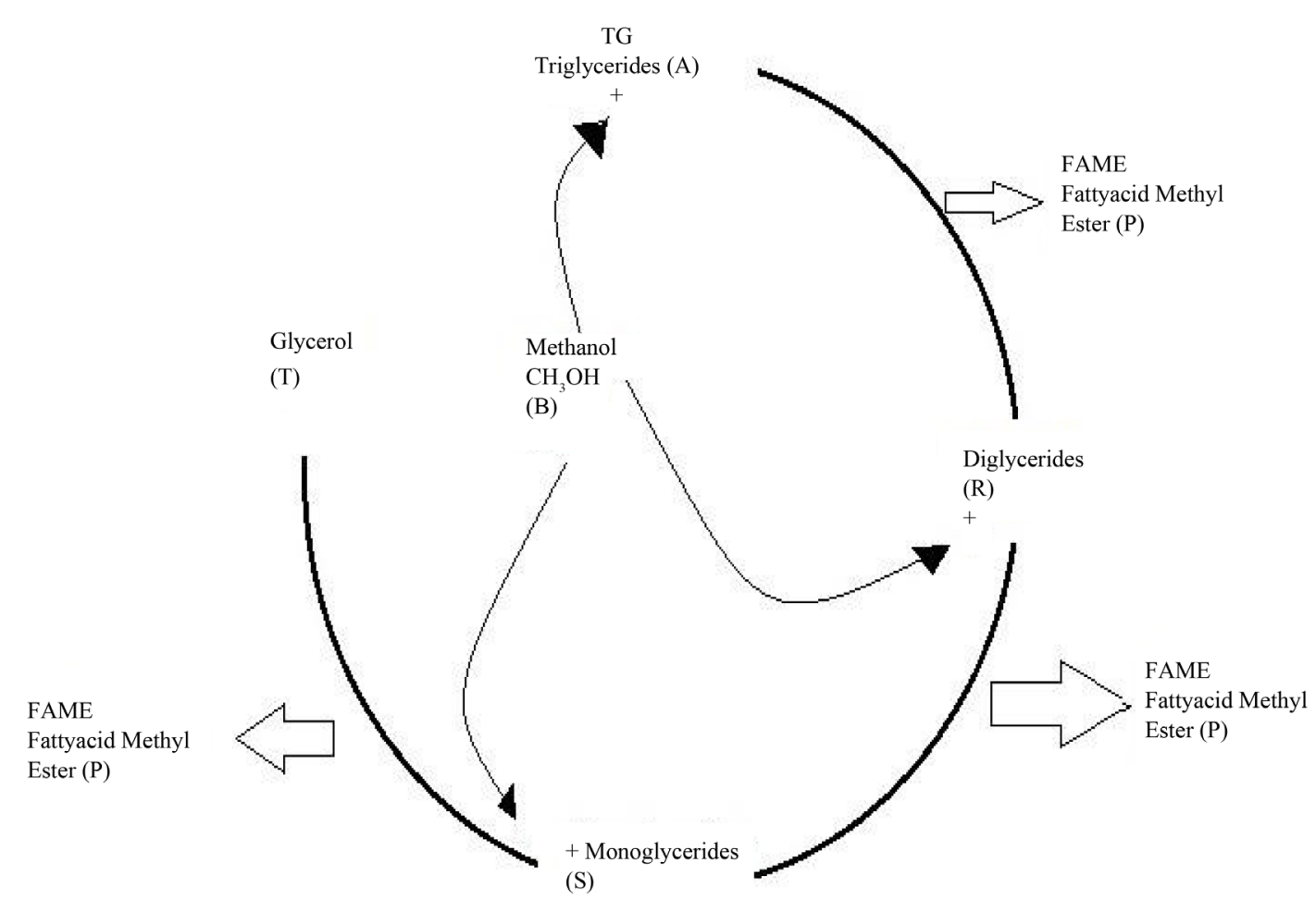

Figure 1. Transesterification catalyzed reactions from triglycerides to glycerin and FAME.

$$
\begin{gathered}
\frac{\mathrm{d} X_{A}}{\mathrm{~d} \tau}=1-X_{A} \\
\frac{\mathrm{d} X_{R}}{\mathrm{~d} \tau}=1-X_{A}-\kappa X_{R} \\
\frac{\mathrm{d} X_{S}}{\mathrm{~d} \tau}=\kappa X-\omega X_{S} \\
\frac{\mathrm{d} X_{T}}{\mathrm{~d} \tau}=\omega X_{S}
\end{gathered}
$$

The rate expression for the product, FAME can be obtained by adding the contributions from the methanolysis of triglyceride, diglyceride and monoglyceride steps and can be seen to be:

$$
\frac{\mathrm{d} X_{P}}{\mathrm{~d} \tau}=1-X_{A}+\kappa X_{R}+\omega X_{S}
$$

In order to evaluate the selectivity of the FAME product $\mathrm{P}$ over the by-product, glycerin, T solution to Equations (8)-(12) were obtained by the method of Laplace transforms. The solutions are as follows:

$$
\begin{gathered}
X_{A}(s)=\frac{1}{s(s+1)} \\
X_{A}(\tau)=\left(1-\mathrm{e}^{-\tau}\right) \\
X_{R}(s)=\frac{1}{(s+\kappa)(s+1)} \\
X_{R}(\tau)=\frac{1}{(1-\kappa)}\left(\mathrm{e}^{-\kappa \tau}-\mathrm{e}^{-\tau}\right)
\end{gathered}
$$




$$
\begin{gathered}
X_{S}(s)=\frac{\kappa}{(s+\kappa)(s+1)(s+\omega)} \\
X_{S}(\tau)=\frac{1}{(1-\kappa)(1-\omega)(\kappa)}\left((1-\kappa) \mathrm{e}^{-\omega \tau}-(1-\omega) \mathrm{e}^{-\kappa \tau}-(\kappa-\omega) \mathrm{e}^{-\tau}\right) \\
X_{T}(s)=\frac{\omega \kappa}{(s)(s+\kappa)(s+1)(s+\omega)} \\
X_{T}(\tau)=\frac{\omega \kappa}{(1-\kappa)(1-\omega)(\kappa)}\left((1-\kappa)\left(1-\mathrm{e}^{-\omega \tau}\right)-(1-\omega)\left(1-\mathrm{e}^{-\kappa \tau}\right)+(\kappa-\omega)\left(1-\mathrm{e}^{-\tau}\right)\right)
\end{gathered}
$$

The product yield can be found by difference as:

$$
X_{p}=X_{A}-X_{R}-X_{S}-X_{T}
$$

Model solutions given by Equations (13)-(17) were plotted in Microsoft Excel 2010 for Windows 7.0 on a Hewlett Packard Compaq Elite 8300 desktop computer with Intel Core i7 processor with $3.9 \mathrm{GHz}$ speed. The results for the product distribution is shown in Figures 2-5. The simulations were conducted for values of reaction rate constant ratios $\kappa<1$ and $\omega<1$ and further for $\omega<\kappa$.

It can be seen from Figures 2-5 that the conversion of species $\mathrm{A}, \mathrm{X}_{\mathrm{A}}$ increases in a monotonic manner as predicted in Equation (13). The monoglyceride and diglyceride yields go through a maxima. A change in curvature from convex to concave can be seen in the product yields of FAME and glycerin. There is a rate increase later in time in the formation of glycerin. The selectivity of FAME can be poor compared with glycerin formation as can be seen in Figure 4. FAME yield can be high as shown in Figure 2 and Figure 3. There can also be cross-over

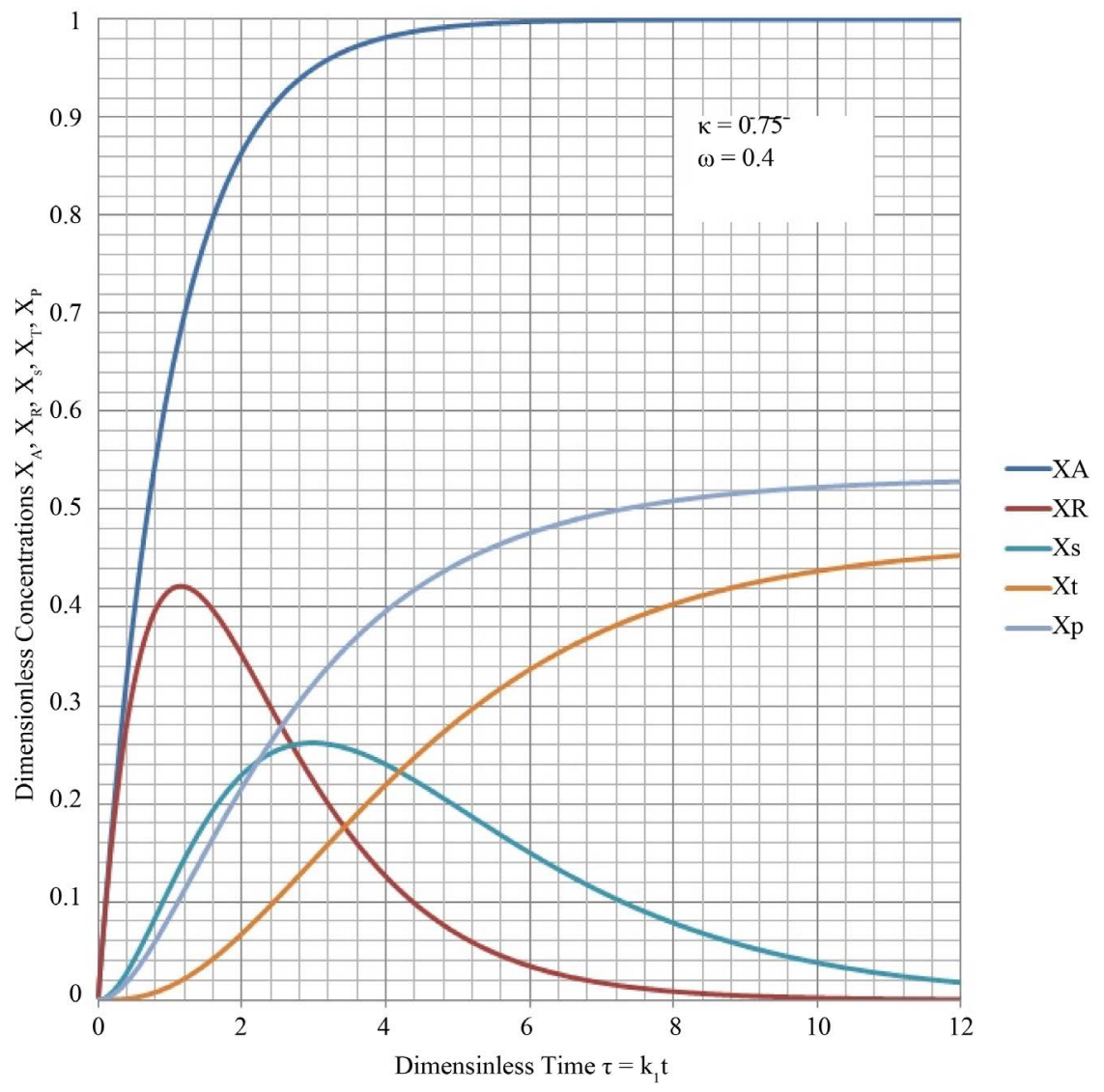

Figure 2. Trigylceride (A), Diglyceride (R), Monoglyceride (S), Glycerin (T) and FAME (P) Product Distribution in progressive methanolysis at $\kappa=0.75$ and $\omega=0.4$. 


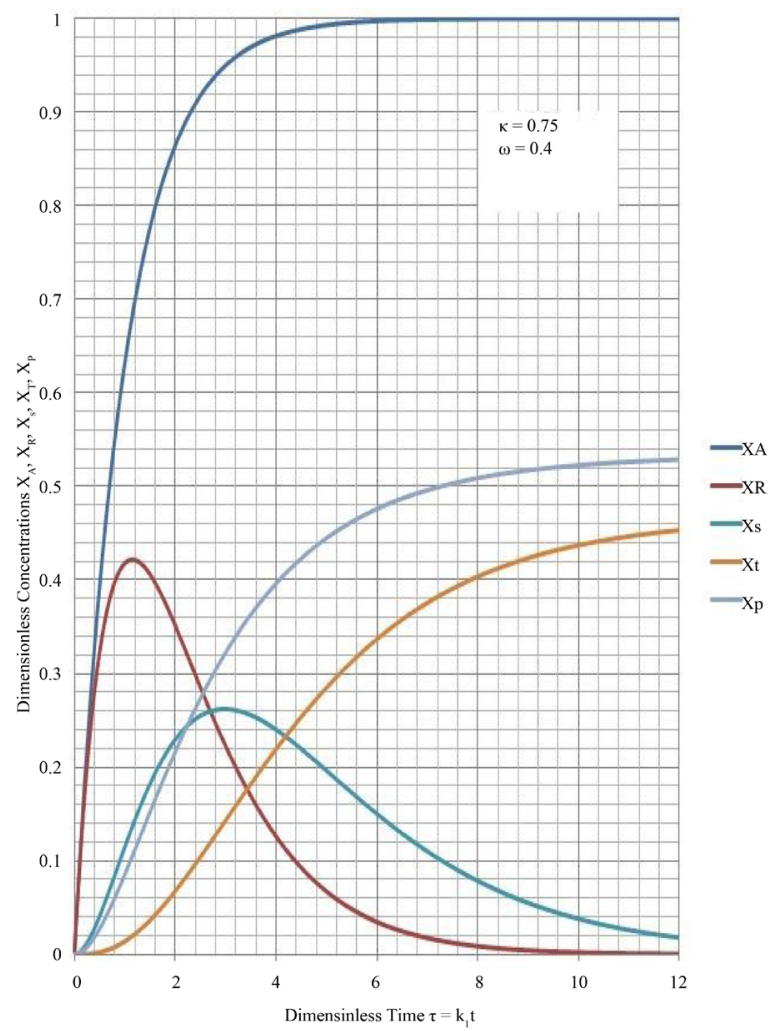

Figure 3. Trigylceride (A), Diglyceride (R), Monoglyceride (S), Glycerin (T) and FAME (P) Product Distribution in progressive methanolysis at $\kappa=0.75$ and $\omega=0.6$.

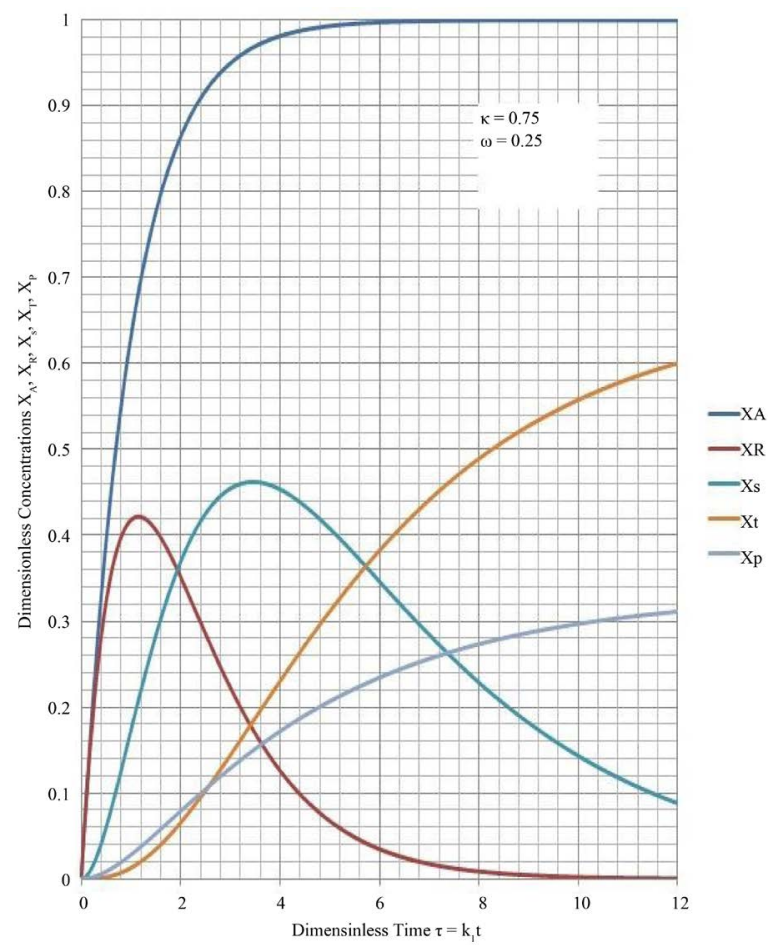

Figure 4. Trigylceride (A), Diglyceride (R), Monoglyceride (S), Glycerin (T) and FAME (P) Product Distribution in progressive methanolysis at $\kappa=0.75$ and $\omega=0.25$. 


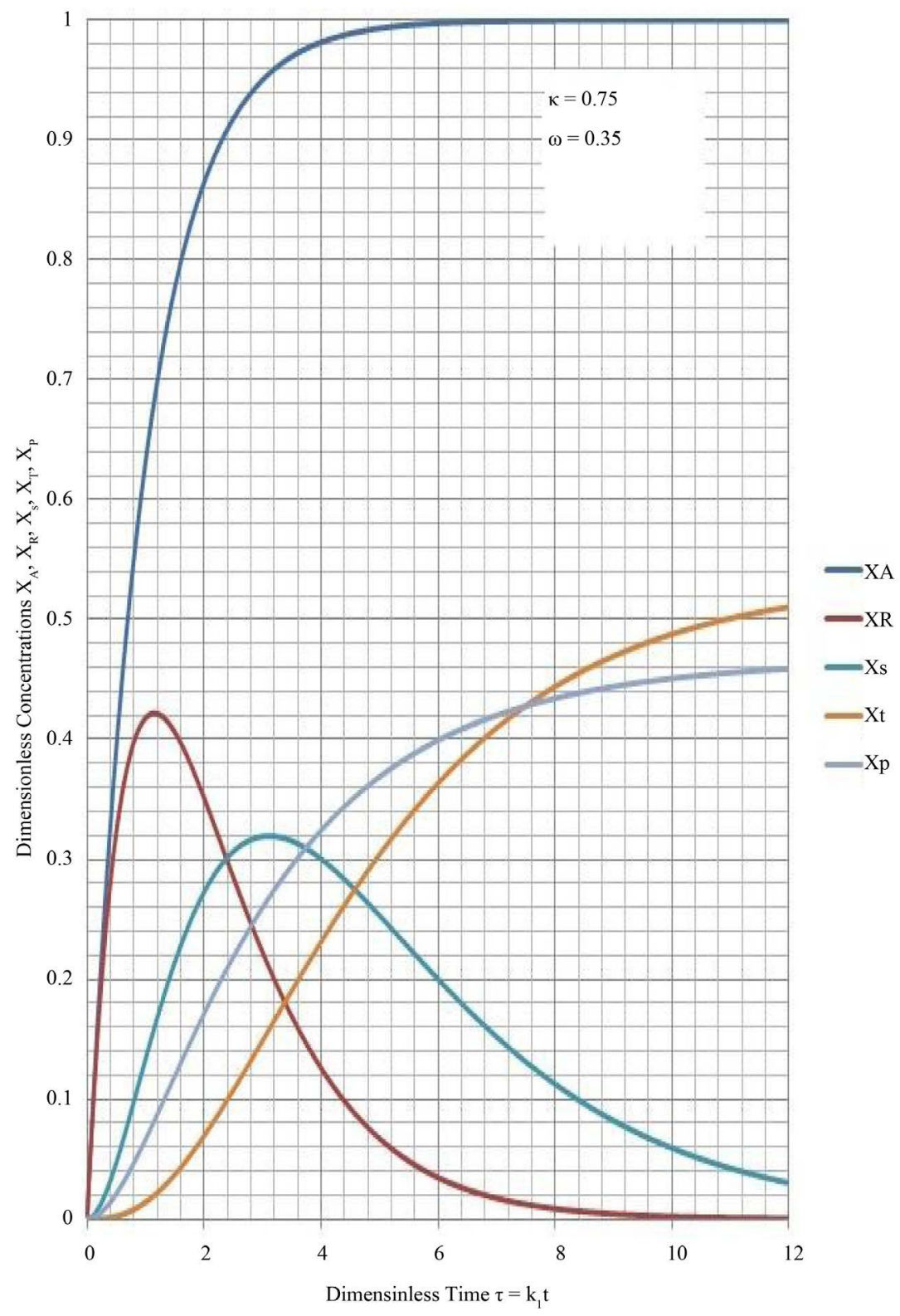

Figure 5. Trigylceride (A), Diglyceride (R), Monoglyceride (S), Glycerin (T) and FAME (P) Product Distribution in progressive methanolysis at $\kappa=0.75$ and $\omega=0.35$.

from higher selectivity of FAME to lower selectivity of FAME compared with glycerin as can be seen in Figure 5. In such cases, CSTR can be used with residence times less than the cross-over point in order to obtain higher yield of FAME. The convexo-concave curvature in the product yields is consistent with experimental studies such as that reported by Jaya and Ethirajulu [22].

\section{Conclusions}

With the depletion of oil reserves, pollution and global warming caused by increase usage of petroleum alternate energy sources are sought after in order to preserve the energy security of the nation and the world. Biodiesel is a renewable fuel. One of the methods of preparation of biodiesel is the transesterification of triacylglycerols in vegetable oil or animal fat with an alcohol such as methanol in the presence of an alkali or acid catalyst. The products are FAME (s) and are called biodiesel. Glycerin is formed as byproduct. Alkali catalysts used are 
$\mathrm{NaOH}$ or $\mathrm{KOH}$.

Three synthesis methods are reported for commercial manufacture of biodiesel. These are: 1) transesterification of vegetable oil; 2) Pyrolysis of vegetable oil; 3) Physical blending and emulsification. Spectrum of different feedstock types has been used for the vegetable oil. This ranges from waste cooking oil to jatorpa crop cultivated with a targeted purpose of generating fuel. Feedstock types used are: a) Soybean oil; b) Rapseed oil; c) Sun flower oil; d) Coconut oil; e) Palm oil; f) Tung oil.

FAME is produced upon transesterification of vegetable oil. A two or three stage process of reaction and centrifugal separation is used. Centrifugal separation is used to separate the glycerin and biodiesel layers by gravity differences. More degree of separation can be achieved by increased torque of the rotor (Sharma [6]). Pyrolysis usually involves heating in the absence of oxygen. Soybean oil is thermally decomposed and separated by distillation. About $75 \%$ of the distillate is hydrocarbons such as alkanes and alkenes. Vegetable oils can be catalytically cracked into useful fuels. Catalyst used is silica/alumina and palm and copra oils are used. Condensed organic phase can be fractionated into biogasoline and biodiesel. Microemulsions of vegetable oil with solvents such as methanol are studied. Microemulsion is defined [10] as a dispersion of optically isotropic fluid microstructures in 1 - $150 \mathrm{~nm}$ size range in colloidal equilibrium when two normally immiscible liquids and amphiphiles are mixed.

The expected growth rate of biodiesel production in the world is about 6\% between 2009-2018 according to OECD, Organization for Economic Cooperation and Development. By 2017, biodiesel production is expected at 25 billion liters.

European biodiesel board estimated that the production of biodiesel in EU was about 9.6 milllion tons in 2010. President of India has called for crops with increased yield of biodiesel. President B. Obama has endorsed the biodiesel fuel industry by offering tax credits to the farmers and suppliers. The reactions in the reactor during biodiesel production may be modeled as scheme of multiple reactions of the consecutive-competitive/series-parallel type [14]. The methanol can be assumed to be in excess. The scheme of reactions is shown in Figure 1.

The four ordinary differential equations in Equation (2) can be written in the state space form (Equation (3)). The system can be seen to be the integrating type given the values of the eingenvalues. This is an example of three-step reaction where the product $\mathrm{P}$ for FAME and by-product, $\mathrm{T}$ for glycerol are desired. The addition policy of methanol along the length in case of PFR and the timings in the case of CSTR, continuous stirred tank reactor can influence the product mix. The method of mixing the reactants such as slow mixing of $\mathrm{A}$ to $\mathrm{B}$, slow mixing of B to A and rapid mixing of A and B may be important design criteria. In order to obtain more yield of $\mathrm{P}$ the points where $\mathrm{R}$ and $\mathrm{S}$ will reach a maxima need be avoided as operating points. The cost of raw materials is a critical factor in the profitability of biodiesel manufacture. The AW analysis of a biodiesel factory in Taiwan operated in 2004 is completed using a MS Excel spreadsheet as shown in Table 2. It can be seen that the material cost and by-product credit are critical to the profitability of biodiesel. A summary of the capital investment, process cost, revenue accrued of the three different plants are shown in Table 3 . These plants have been operated in the batch and continuous mode. Careful evaluation of batch vs. continuous mode has not been done. Plant I has been found to be more profitable compared with Plant II and Plant III. It is not clear whether this is because of the larger size and continuous production [23]. The selectivity of FAME over glycerin was obtained from model solutions by method of Laplace Transforms. Product distribution curves for triglycerides, diglycerides, monoglycerides, glycerin and FAME are presented in Figures 2-5. Formation of FAME is after competition for feed A with glycerin formation. Reactor choice, residence time, temperature can be arrived at in order to obtain higher yield of FAME compared with glycerin. This may increase the profitability of biodiesel production.

\section{Acknowledgements}

Acknowledgements are extended to my students in CHEG 2003, Economic Analysis and Technical Applications class at Prairie View a \& M University, Prairie View, TX. This study was a natural extension of the worked example for AW estimates in class. Special mention of my chair B. G. Shiva Prasad at the Energy Sustainability Conference at San Francisco, CA 2009 for initiating the overview paper on Energy Sustainability. Special thanks to Prof. R. Turton, West Virginia University, Morgatnwon, WV and Emeritus Prof. O. Levenspiel, Oregon State University, Corvallis, OR for their guidance in design of reactors for consecutive reactions.

\section{References}

[1] Podolski, W.F., Shmalzer, D.K., Conrad, V., Lowenhaupt, D.E., Winschel, R.A., Klunder, E.G., Mcllvried III, H.G., 
Ramezan, M., Stiegel, G.J., Srivastave, R.D., Winslow, J., Loftus, P.J., Benson, C.E., Wheeldon, J.M., Krumpelt, M. and Lee-Smith, F. (2008) Energy Resources, Conversion, and Utilization. In: Gren, D.W. and Perry, R.H., Eds., Perry’s Chemical Engineers' Handbook, McGraw-Hill, New York.

[2] (2005) Congressional Record. Vol. 151, Part 4, 4544.

[3] Shay, E.G. (1993) Diesel Fuel from Vegetable Oils: Status and Opportunities. Biomass and Bioenergy, 4, $227-242$. http://dx.doi.org/10.1016/0961-9534(93)90080-N

[4] Abraham, M.A. and Nguyen, N. (2005) Results from the Sandestin Conference: Green Engineering: Defining Principle. Environmental Progress, 22, 233-236. http://dx.doi.org/10.1002/ep.670220410

[5] Krawczyk, T. (1996) Biodiesel—Alternative Fuel Makes Inroads But Hurdles Remain. INFORM, 7, 801-829.

[6] Sharma, K.R. (2012) Power Draw of the Rotor during Centrifugal High Volume Separation of Oil and Water. Journal of Mechanical Engineering Research, 4, 10-16. http://www.academicjournals.org/jmer/PDF/Pdf2012/January/Sharma.pdf.

[7] Connemann, J., Krallmann, A. and Fischer, E. (1994) Process for the Continuous Production of Lower Alkyl Esters of Higher Fatty Acids. US Patent No. 5354878.

[8] Martin, A., Flynn, J.E. and Lange, H. (2011) Biodiesel Production Method. B \& P Process Equipment and Systems, LLC, Saginaw, US Patent No. 8030505.

[9] Kulkarni, M.G. and Dalai, A.K. (2006) Waste Cooking Oil—An Economic Source for Biodiesel: A Review. Industrial \& Engineering Chemistry, 45, 2901-2913.

[10] Ma, F. and Hanna, M.A. (1999) Biodiesel Production: A Review. Bioresource Technology, 70, 1-15.

[11] Sharma, K.R. (2011) Fundamentals of Engineering Economics. Cognella Academic Publishers, San Diego.

[12] Indian Wild Ass Sanctuary. The Hindu, Chennai, February 27th, 2006.

[13] Moran, S. (2006) Biodiesel Comes of Age as the Demand Rises. New York Times, September 12th, 2006.

[14] Levenspiel, O. (1999) Chemical Reaction Engineering. John Wiley \& Sons, Hoboken.

[15] Sharma, K.R. (2012) Process Instrumentation, Dynamics and Control. Cognella Academic Publishers, San Diego.

[16] Bender, M. (1999) Economic Feasibility Review for Communit-Scale Farmer Cooperatives for Biodiesel. Bioresource Technology, 70, 81-87. http://dx.doi.org/10.1016/S0960-8524(99)00009-7

[17] Weber, J.A. (1993) The Economic Feasibiloty of Community-Based Biodiesel Plants. Master’s Thesis, University of Missouri, Columbia.

[18] Nelson, R.G. and Shrock, M.G. (1993) Energetic and Economic Feasibility Associated with the Production, Processing and Conversion of Beef Tallow to Diesel Fuel. In: Proceedings of the First Biomass Conference of the Americas: Energy, Environment, Agriculture and Industry, Volume 2, NREL, National Renewable Energy Laboratory, Golden, 848-862.

[19] You, Y.D., Shie, J.L., Chang, C.Y., Huang, S.H., Pai, C.Y., Yu, Y.H. and Chang, C.H. (2008) Economic Cost Analysis of Biodiesel Production: Case in Soybean Oil. Energy \& Fuels, 22, 182-189. http://dx.doi.org/10.1021/ef700295c

[20] Turton, R., Bailie, R.C., Whiting, W.B. and Shaeiwitz, J.A. (1998) Analysis, Synthesis, and Design of Chemical Processes. Prentice Hall, Upper Saddle River.

[21] Darnoko, D. and Cheryan, M. (2000) Continous Production of Palm Methyl Esters. Journal of American Oil Chemists Society, 77, 1269-1272.

[22] Jaya, N. and Ethirajulu, K. (2011) Kinetic Modeling of Transesterification Reaction for Biodiesel Production Using Heterogeneous Catalyst. International Journal of Engineering Science, 3, 3463-3466.

[23] Shiva Prasad, B.G. and Sharma, K.R. (2012) Alternative Energy for Energy Sustainability. Annals of Arid Zone, April 2012. 